\title{
PENERAPAN STRATEGI BRANDING DENGAN PEMAHAMAN BACAAN GEOFFREY BROADBENT DAN J.M. BOCHENSKI PADA HUNIAN GREEN DI JAKARTA
}

\author{
Sarah Aisha ${ }^{1}$, Rafi Mentari ${ }^{2}$, Marselly Dwiputri ${ }^{3}$ \\ ${ }^{1}$ Universitas Indraprasta PGRI, Program Studi Arsitektur \\ sarachaisha@gmail.com \\ ${ }^{2}$ Universitas Indraprasta PGRI, Program Studi Arsitektur \\ rafimentari@gmail.com \\ ${ }^{3}$ Universitas Indraprasta PGRI, Program Studi Arsitektur \\ marselly_dwiputri@yahoo.com
}

\begin{abstract}
Along with the development of residential developments in Jakarta, developers have started to carry out branding strategies for property products being sold. Brand is an identity or name that represents the product as a whole, whether the product itself, the services provided by the product, the company that produces it, or other related things. While branding is a form of strategy, method, method or effort to convey a product's brand to consumers, so that the product is recognized by the public. Reflecting on the failure of a branding strategy process in Pruitt-Igoe, where it assumes that a good physical design and branding strategy can be a determinant of the success or failure of public housing, it is important to explore the extent of branding strategy and design in residential development practice in Jakarta. the results of research on branding strategies for residential projects in Jakarta by showing a rational and empirical attitude according to the reading comprehension of Geoffrey Boradbent and JM Bochenski, namely: Knowing the application of branding strategies with a rational / empirical / both attitude towards housing in Jakarta. This study used a qualitative method, where the qualitative method was through direct observation of several residential objects that were randomly selected.
\end{abstract}

Key Words: branding strategy, rational, empirical, occupancy, property

\begin{abstract}
Abstrak : Seiring berkembangnya pembangunan hunian di Jakarta, para pengembang mulai melakukan strategi branding terhadap produk property yang dijual. Brand merupakan identitas atau nama yang mewakili produk secara keseluruhan baik produk itu sendiri, jasa yang diberikan produk tersebut, perusahaan yang memproduksi, maupun hal-hal terkait lainnya. Sedangkan branding adalah bentuk strategi, metode, cara atau upaya menyampaikan Brand sebuah produk kepada konsumen, agar produk tersebut dikenali oleh masyarakat. Berkaca kegagalan pada suatu proses strategi branding di Pruitt-Igoe dimana disana mengandaikan bahwa desain fisik dan strategi branding yang baik dapat menjadi penentu keberhasilan atau kegagalan hunian publik, Penting untuk ditelusuri sejauh strategi Branding serta desain dalam praktik pengembangan hunian di Jakarta.. Tulisan ini membahas hasil penelitian tentang strategi branding terhadap proyek hunian di Jakarta dengan menunjukkan sikap rasional dan empiris sesuai pemahaman bacaan Geoffrey Boradbent dan J.M. Bocheński yaitu: Mengetahui penerapan strategi branding dengan sikap rasional/empiris/keduanya terhadap hunian di jakarta. Penelitian ini menggunakan metode kualitatif, dimana metode kualitatif melalui pengamatan langsung terhadap beberapa objek hunian yang dipilih secara acak.
\end{abstract}

Kata Kunci : strategi branding, rational, empiris, hunian, property

\section{PENDAHULUAN}

Beberapa dekade belakangan ini, strategi branding dalam usaha pengembangan proyek perumahan seringkali mengangkat brand gaya hidup, salah satunya adalah Green. (Green Building Council ndonesia, 2014) Fenomena ini menjadi menarik untuk diamati menyangkut bagaimana strategi branding yang dilakukan dengan mengaitkannya terhadap sikap rasional dan empiris. Dalam mengembangkan dan merancang perumahan, memungkinkan untuk menunjukkan sikap. Hal tersebut dapat dikombinasikan, namun biasanya keduanya berdiri sendiri.

DKI Jakarta sebagai lokasi penelitian merupakan ibukota Negara Indonesia dimana pertumbuhannya terus meningkat dari waktu ke waktu, dimana pada tahun 2017 memiliki kepadatan penduduk yang tinggi, yaitu : 15 366,87 jiwa/km (Badan Pusat Statistik Provinsi DKI 
Jakarta, n.d.) dengan tingkat pertumbuhan sebesar 1,02 persen per tahun (2017) (Badan Pusat Stratistik Provinsi DKI Jakarta, 2018). Jabodetabek (sebuah wilayah megapolitan yang terdiri dari Jakarta, Bogor, Depok, Tangerang, Bekasi) membutuhkan rumah dalam jumlah besar dari tahun ke tahun. Sebagian besar pembangunan dan pengadaan rumah di Jabodetabek (juga di Indonesia) diselenggarakan oleh perusahaanperusahaan.

Branding adalah sebuah strategi dan upaya menyampaikan brand sebuah produk (termasuk produk properti) kepada konsumen, agar produk tersebut dikenal dan kemudian banyak dikonsumsi oleh masyarakat. Strategi branding diperlukan para developer terutama pada penjualan produk yang bersifat jangka panjang. Selain itu melalui strategi branding, developer menjaring komunitas untuk memberikan diferensiasi dan tujuan kepada konsumen (Aaker, David A.; Joachimsthaler, Erich, 2012). Seperti disebutkan sebelumnya, strategi branding dalam usaha pengembangan proyek perumahan seringkali mengangkat topik gaya hidup, salah satunya adalah 'Green'.

Worm dalam penelitiannya menjelaskan bahwa kekuatan dari branding menjadi salah satu komponen bagi pelanggan yang dapat mempengaruhi kinerja produsen sehingga mereka saling memiliki kerterkaitan satu sama lain. (Worm, Stefan, 2012).

Dalam mendevelop suatu hunian, Geoffrey Boradbent mengungkapkan bahwa memungkinkan untuk menunjukkan sikap rasional ataupun empiris. Hal tersebut dapat dikombinasikan, namun biasanya mereka berdiri sendiri. (Boradbent, Geoffrey;, 1988)

Para rasionalis akan lebih cenderung ke sesuatu yang abstrak, hanya terdapat didalam pikiran dan tidak dapat dihubungkan dengan indra manusia, yang berupa indra penglihatan, pendengaran, penciuman, perasa, dan peraba. Ia lebih kepada kemampuan berpikir berdasarkan akal sehat. Sementara itu, para empiris akan lebih memperhatikan hal yang real; memusatkan kepada pengalaman yang terhubung oleh sensor indra dengan mengesampingkan rasionalitas. (Boradbent, Geoffrey;, 1988)

Terminologi dengan makna yang tepat dibutuhkan untuk memberikan kejelasan dari teori metodologi kontemporer. Oleh (Bocheński, 1968), terminologi dibedakan menjadi tiga bagian, yaitu: 1. Terminologi Ontologi
Terdiri dari hal-hal yang ditandai dengan hal-hal yang biasa disebut dengan "being" terbagi dalam aspek eksistensi yang berupa kehadirandiakui, ada karena sesuatu dari esensi yang merupakan konsep suatu kehadiran tersebut.

\section{Terminologi Psikologi}

Berkaitan dengan bidang pengetahuan berupa perilaku mental, karena hanya dapat ditemukan didalam pikiran manusia dari suatu kondisi keadaan berupa objek maupun subjek yang tergambarkan. Secara subjektif terdapat pola mental yang merupakan bagian dari pikiran manusia, namun secara objektif menjadi sebuah pertanyaan dari apa yang mewakili konten pola tersebut.

Namun, perlu membedakan antara perolehan pengetahuan dan pemikiran. Pemikiran akan memberikan keterlibatan yang lebih luas, sedangkan pengetahuan diperoleh karena adanya pemahaman yang terjadi melalui suatu proses mental dan akhirnya menghasilkan pengetahuan.

\section{Terminologi Semiotik}

Selain berupa bahasa tulisan atau lisan, terdapat tanda (sign) yang digunakan untuk mengkomunikasikan konsep maupun asumsi kepada orang lain, serta untuk membuat pemikiran kita tentang sesuatu menjadi lebih mudah.

Bahasa kepada tanda tidak mewakili halhal secara langsung, tetapi lebih kepada bagaimana kita berpendapat tentang hal-hal tersebut dengan konsep objektif dan asumsi objektif. Bila gagal dalam menjelaskannya, dapat menyebabkan kesalah pahaman, karena bahasa kepada tanda dapat diartikan sebagai sesuatu yang ambigu maupun sesuatu yang mewakili benda dengan kemiripan yang sama.

Fokus penelitian adalah perumahan tapak yang dikembangkan oleh swasta yang tergabung dalam Real Estate Indonesia/REI.

\section{METODOLOGI}

Metode yang digunakan adalah Qualitative method, yaitu metode penelitian dengan melakukan pengamatan langsung terhadap objek penelitian (Creswell, John W.).

\section{HASIL DAN PEMBAHASAN}

Dari buku Direktori REI tahun 2011 dan 2015, diperoleh data bahwa terdapat sebanyak 42 proyek perumahan yang dikembangkan REI di Jakarta sebagai sampel penelitian. 
Dalam penelitian (Aisha \& Susanto, 2018) 42 perumahan yang ada di Jakarta, sebanyak $73 \%$ menggunakan topik Product Image dan dijelaskan bahwa $42 \%$ atau 18 hunian menggunakan sub topik Green.

Tabel 1. Hunian dengan sub topik Green

\begin{tabular}{|l|l|c|c|c|}
\hline No & $\begin{array}{c}\text { Nama } \\
\text { Proyek }\end{array}$ & Ontologi & Psikologi & Semiotik \\
\hline 1 & JGC & 0 & I & I \\
\hline 2 & PBR & 0 & I & I \\
\hline 3 & TA & 0 & I & I \\
\hline 4 & TDM & 0 & I & I \\
\hline 5 & CGC & 0 & I & I \\
\hline 6 & GM & 0 & I & I \\
\hline 7 & GGK & 0 & I & I \\
\hline 8 & BGM & 0 & I & I \\
\hline 9 & GLC & 0 & I & I \\
\hline 10 & RVR & 0 & I & I \\
\hline 11 & GLR & 0 & I & I \\
\hline 12 & GV & 0 & I & I \\
\hline 13 & MR & 0 & 0 & 0 \\
\hline 14 & GP & 0 & I & I \\
\hline 15 & BIG & 0 & I & I \\
\hline 16 & TSI & 0 & I & I \\
\hline 17 & BP & 0 & 0 & 0 \\
\hline 18 & TG & 0 & I & I \\
\hline
\end{tabular}

\section{Keterangan:}

JGC: Jakarta Garden City; PBR: Puri Botanical Residence; TA:Taman Aries; TDM: Taman Duta Mas; CGC: Citra Garden City; GM: Green Mansion; GGK: Green Garden Kedoya; BGM: Bukit Golf Mediterania; GLC: Green Lake City; GP: Green Puri; RVR: River Valley Residence; GLR: Golf Lake Residence; GV: Green Village, MR: Matoa Residence; BIG: Bona Indah Garden; TSI: Taman Semanan Indah; BP: Bukit Pratama; TG: Taman Grisenda

Tabel 1 menjelaskan bahwa Penulis mengaitkan 18 hunan yang bertemakan Green kedalam terminology sebagai upaya mendapatkan kejelasan antara teori yang digunakan terhadap realita strategi branding yang dilakukan oleh pengembang.

Dari 18 sampel tersebut, 2 diantaranya tidak masuk ke dalam terminologi psikologi karena secara strategi branding yang dilakukan tidak terlalu menonjolkan unsur Nature/Green yang kental. Sehingga jika dikaitkan ke dalam kajian psikologi, belum menggambarkan bahwa objek tersebut mempengaruhi pemikiran calon pembeli bahwa hunian tersebut termasuk ke dalam hunian yang melakukan strategi branding Nature/Green.

Pada terminology Semiotik 2 diantaranya tidak masuk ke dalam terminologi semiotic, karena belum terdapat tanda (sign) yang digunakan sebagai salah satu strategi branding dalam mengkomunikasikan konsep maupun asumsi kepada calon pembeli, serta untuk membuat pemikiran kita tentang sesuatu menjadi lebih mudah. Seperti kata "Bukit dan Matoa".

\section{PENUTUP Simpulan}

Penelitian ini menggambarkan bahwa hunian dengan strategi branding Nature/Green harus dipikirkan secara maksimal dan matang dengan sikap rasional dan empiris agar pesan dan tujuan yang ingin disampaikan pengembang bisa sampai kepada konsumen.

Dari penelitian yang dilakukan oleh peneliti, kesimpulan yang dapat di ambil adalah :

a) Dari $90 \%$ atau sekitar 16 hunian Nature/Green di Jakarta sudah cukup bagik dalam melakukan srtategi Branding melalui pendekatan Psikologis dan Semiotik

b) Para Developer sudah menunjukkan sikap empiris dengan memperhatikan hal yang real; memusatkan kepada pengalaman yang terhubung oleh sensor indra dengan mengesampingkan rasionalitas.

c) Selain empiris, developer juga telah mengkombinasikan sikap rasional dan empiris nya dengan menanamkan ke psikologis calon pembeli terhadap produk yang dijual, kemudian mengaplikasikan langsung ke dalam hunian.

\section{Saran}

Penelitian ini merupakan penelitian lanjutan terhadap penelitian yang sudah ada terkait strategi Branding pada hunian Nature/Green, namun kedepannya penelitian ini dapat dikembangkan untuk penelitian perumahan dengan brand selain Nature/Green di daerah lain, terutama kota-kota besar yang tingkat kepadatan penduduknya tinggi.

\section{DAFTAR PUSTAKA}

Aaker, David A.; Joachimsthaler, Erich. (2012). Brand Leadership. New York: Free Press. Aisha, S., \& Susanto, D. (2018). Green Estate in Jakarta: Branding or Reality. International Tropical Renewable Energy Conference. Depok: Universitas Indonesia.

Badan Pusat Statistik Provinsi DKI Jakarta. (n.d.). Retrieved March 9, 2018, from https://jakarta.bps.go.id/statictable/2017/ 01/30/138/distribusi-dan-kepadatan- 
140 Penerapan Strategi Branding dengan Pemahaman Bacaan Geoffrey Broadbent dan J.M. Bochenski pada Hunian Green di Jakarta

penduduk-menurut-kabupaten-kota-di-

provinsi-dki-jakarta-2015.html

Badan Pusat Stratistik Provinsi DKI Jakarta. (2018). (Badan Pusat Statistik) Retrieved May 8, 2018, from https://jakarta.bps.go.id/statictable/2017/ 01/30/136/jumlah-penduduk-dan-lajupertumbuhan-penduduk-menurutkabupaten-kota-di-provinsi-dki-jakarta2010-2014-dan-2015.html

Bocheński, J. (1968). The Methods of Contemporary Thought. New York, United States of America: Harper \& Row.

Boradbent, Geoffrey;. (1988). Design in Architecture: Architecture and The Human Science (Vol. Chapter 4). London: David Fulton.

Creswell, John W. (n.d.). Third Edition Qualitative, Quantitative, and Mixed Methods Approaches. California: SAGE Publication.

Green Building Council ndonesia. (2014, August). Retrieved March 21, 2018, from http://www.gbcindonesia.org/

Worm, Stefan. (2012). Branded Component Strategies : Ingredient Branding in B2B Markets. 